\title{
From the Interruption to the Development of Language Awareness in Translation: Questioning Cognitive and Educational Issues
}

\author{
Nalan Büyükkantarcioğlu* \& Aymil Doğan ** \\ Haceteppe University Ankara Turkey
}

This paper, emphasizing the importance of native language awareness in translation and drawing on problems observed in university students, sets out with an assumption that native language awareness, which is supposed to have satisfactorily developed either naturally or through previous stages of education, may undergo a serious process of "interruption" or "blockage”, as we call it, during written translations made particularly from the source language (English) to the mother tongue (Turkish). The fact that students can recognize their mother tongue mistakes either after self-monitoring or after the instructor's remarks may indicate that translated texts, which are seemingly Turkish, yet lacking many of the naturally well-formed features of the mother tongue discourse, suffer from such problems either due to the heavy concentration of mind on the source language structures or due to the problems originating from the gaps in the translation training. Performances of a total of 60 subjects, comprising an equal number of freshman and senior students from two different departments at Hacettepe University - Department of Linguistics and Department of Translation and Interpretation - have been compared through tests of English, mother tongue awareness and translation to find out (a) what actual reasons lie behind the problem, (b) whether there is any positive improvement from the freshman to the senior groups in both departments, and $(c)$ whether extensive translation training marks a positive effect on students to help them avoid problems concerning native language awareness.

\section{Introduction}

One of the important assests of a translator is the ability to perceive and express reality through the perspectives of two different linguistic systems. Each linguistic system has not only its own lexical, syntactic, semantic or phonological features, but also presents socially and culturally grounded ways of expression in its own discourse. Although the foreign language in this context may be thought to present more barriers for a translator, the opposite, that is, the problems with the native language, may present equally important barriers in certain cases. No matter how well a native speaker is

* Assoc. Prof. Dr., Hacettepe University, Faculty of Letters, Department of Linguistics, Beytepe, Ankara, Turkey.

** Assist. Prof. Dr., Hacettepe University, Faculty of Letters, Department of Translation and Interpretation, Beytepe, Ankara, Turkey. 
assumed to have mastered his mother tongue, the ability to develop a conscious control over one's implicit knowledge is a different issue, relating to psychological, cognitive and educational processes. Experiments with students in translation courses have shown us that a considerable number of problems in the translated texts originate from the poor quality of such a conscious control. In other words, many of the texts translated from English into Turkish display sentences that are neither in accordance with the naturally well-formed or socio-culturally acceptable syntactic and semantic constructions in Turkish, nor do they present adequate lexical selections. The problem, in most cases, has little to do with foreign language grammar or comprehension. Even if the translating student presents good evidence that the original text has been well-understood, the outcome is a "seemingly" Turkish text, showing that the semantic deep structures in the original text have been unsuccessfully transferred to the socio-culturally and linguistically acceptable surface structures in Turkish. The reason for this problem may be two-fold: Either the student's mind is loaded or dominated by the foreign language structures at the time of translation, thus they affect his strategies of perception and expression, or he has really a poor level of language awareness, thus cannot differentiate between ill- and well-formed structures at all. For a student in the first case, self-correction is possible. Such a student may feel content with his translation first, but after a careful monitoring or the instructor's consciousness-raising remarks, he recognises the problems and is usually surprised to have produced constructions that a native speaker would normally not produce at all. The problems observed in the first version of the translated text may be due to the complex or misleading cognitive processes taking place in the mind of the translator. Whatever seems to be understandable enough to the translator himself is probably taken to be equally understandable for others. Though it is only an assumption and a detailed explanation requires a cognitive psychologist's perspective, temporary cognitive dominance of the semantic and syntactic constructions or the lexical items in the source language may be blocking the construction of well-formed structures or the selection of appropriate lexical items in the target language. Once the translator frees himself from such a process and re-evaluates his translation with a raised consciousness, the result is usually a success, because he can correct his mistakes and produce a much better text proving to be a successful translation by all standards. This is good evidence for his language awareness (hereinafter LA). As for a student who has difficulty in recognising his mistakes in the mother tongue, the problem indicates a need for language awareness development.

In addition to intuitive judgements and linguistic awareness that ensure good quality of translation, knowledge of translation theories and strategies certainly plays a significant role in the successful construction of the target text. Behind most translation theories and strategies is the covert concept of LA even though the term itself is not always explicitly mentioned. Although various translation strategies give guidelines as to what to translate and how to translate, students may not always fully benefit from theory- 
based instruction unless it is also supported by awareness-raising practices in the mother tongue.

Considering language awareness, an essential autonomy affecting the quality of translations from the foreign language to the mother tongue, in this study, we first emphasize the difference between linguistic awareness and language awareness and then, focusing on the observed problems of translation, present an empirical investigation to shed light on the reasons and ways of solution. Before going on with the details of the study, it may be reasonable to provide a brief account of the two key notions underlying our study.

\section{On the notions Language Awareness and Linguistic Awareness}

The term "language awareness" first appeared in the subject index of Language Teaching abstracting journal, and then Hawkins's book Awareness of Language: An Introduction followed in the same year. It was during the first international LA conference held in Bangor in 1992 that the concept was thoroughly discussed and the Association for Language Awareness was founded. LA became the concern of many interdisciplinary fields, especially after the publication of the journal Language Awareness (Gnutzmann 1997:65). Though the term may have a recent ring about it, attempts to develop the sensitivity of learners to the mother tongue go back to the $80 \mathrm{~s}$, particularly in Germany and Britain, after it was acknowledged that students or school-leavers were actually "illiterates" in their native language. The reaction developed in this context gave rise to the reconstruction of language programs at schools in the following years. After Bernstein's Deficit Hypothesis (see Bernstein 1971-75), which claimed that children of ethnic or working-class families lacked a sufficiently wide range of grammatical constructions and vocabulary to express complex ideas, was abandoned in favour of Labov's Difference Hypothesis (see Labov 1972) during the 70's, all non-standard varieties were regarded as intrinsically equal and the pedagogical implications of the standard variety were given little importance in language classes at schools. Subsequent attempts to develop LA in European countries tried to solve the problems of students via their metalinguistic knowledge and proficiency in the mother tongue. As can be deduced, LA was initially taken as an educational issue aiming to develop language sensitisation of students at schools.

After LA studies had extended over disciplines such as linguistics, cognitive psychology, foreign language teaching, language planning or psychology of learning, the meaning and the function of the term gained new dimensions. An important distinction that helped the term LA gain a finer sense was made between the two types of knowledge: implicit and explicit knowledge. Cognitive psychologist Anderson's (1995) definition was that implicit (or procedural) knowledge is what we know unconsciously and relates to how to do things. Whereas explicit (or declarative) knowledge is something that we can report and we are consciously aware of. The relation 
between these two types of knowledge and their effects on each other have long been a subject of discussion. According to some information-processing researchers, explicit knowledge can turn into implicit knowledge if automated control over explicit knowledge is acquired through practice. On the other hand, a distinction made by Krashen (1979, 1981, 1985a, 1985 b) between "acquisition" and "learning" in his Monitor Model defines the former as an unconscious and the latter as a conscious process, saying just the opposite of the above claim: learnt (explicit) knowledge is never transformed into acquired (implicit) knowledge, but monitors the learner's production. For some others, such as Bialystok (1982), explicit knowledge need not be conscious knowledge and its development is not possible unless implicit or unconscious knowledge is grounded. Based on such discussions, some researchers, on the other hand, think that learning may occur in either direction, for the human brain can function both deductively and inductively (for a detailed explanation on these and related issues, see Multhaup 1997).

Linguists who were inspired by such discussions of cognitive psychologists used LA, first, as a general term to relate to two distinct senses: In its first sense, it meant "a person's sensitivity to and conscious awareness of the nature of language and its role in human life" (Donmall 1985:7 in Little 1997:93). This sense of the term was consistent with reconstructive pedagogical attempts in Europe. The second sense of the term was used to denote basically a psycholinguistic or a cognitive concept, driven by the innate capacity encompassing cognitions and reflections of linguistic concerns. Later these two senses were further distinguished with different terms: The term LA has been conceived merely as part of language education, indicating consciousness-raising efforts to contribute to better learning, to use metalanguage to manipulate the language or to enhance language proficiency. On the other hand, the term linguistic awareness was proposed to refer to the earlier second sense. The individual's ability to judge intuitively the validity of spoken or written utterances with his tacit knowledge of the language, was clearly distinguished from LA.

\section{The Study}

\subsection{Rationale}

In designing the study, we thought that student translations would be one obvious way of gaining insights into (a) the nature of the students' LA, and (b) the effects of translation training on the development of LA. While designing the study, we had the following considerations in mind:

(a) If translation problems originate from the poor grammatical knowledge or comprehension skills of the student in the source language (in our case, English), there will be little or no sense in looking for other reasons for the observed problems in translation. 
(b) If the student has already mastered English well and displays few or no grammar and comprehension problems in general, it may be the case that the observed problems in the mother tongue are either because of the temporary interruption of LA or because of the poor level of LA in students. If the student is good at monitoring mother tongue mistakes and can correct them sometime after the active process of translation, we can think about an interruption phase, which is essentially cognitive. If not, the problem may be pedagogical in origin.

(c) Since one of the purposes of translation training is to equip students with techniques to use receptor language forms expressing the source language meaning in a natural way, we think that such a training should emphasize the development of LA at the same time.

(d) We assume that an extensive translation training has positive effects on the development of LA. Depending on the nature and number of courses given, performance of students who come from the freshman and senior groups of two different language departments offering translation courses can be compared. In our case, these departments are the Department of Linguistics (hereinafter DL), where a limited number of translation courses are given as supplementary to extensive linguistics courses, and the Department of Translation and Interpretation (hereinafter DTI), where the aim is to educate professional translators with an extensive training. The Medium of instruction in each department is English; however, DTI has to use Turkish naturally more often than DL to serve its purpose. Whereas in DL, with the exception of a limited number of translation courses and comparative syntax studies, all other courses are carried out in the English language. Each department provides a 4-year undergraduate education at Hacettepe University, Ankara. It is hypothesized that a positive improvement in LA will be observed among senior students of DTI, who have been exposed to extensive translation training. However, exceptional cases may be observed in either group of students due to individual interests, skills or certain background differences.

\subsection{Method}

In designing the study, the aim was to create a controlled environment in which the materials would be prepared by researchers and tests administered in classroom settings. To check student performances and to be able to make comparisons between the two departments in general and the freshman and senior groups of each department in particular, a total of 60 subjects was selected. Prior to this selection, a bigger group of students was given a mul- 
tiple choice test to measure grammar and comprehension levels in English. The proficiency test, besides checking English grammar, also included sections such as finding general and specific ideas, making inferences, finding a title and the gist, completing ideas and detecting irrelevant ideas, etc. Out of the student body who took the English test, the ones who received at least 70 over 100 were selected as subjects. As a result, freshman and senior groups from each department had a subject group of 15 students. This way, it was nearly assured that the subject group was levelled in terms of their English proficiency.

Other materials used to check translations and LA are as follows:

(a) An upper-intermediate level passage to be translated from English to Turkish. Students were permitted to use their monolingual or bilingual dictionaries (see the appendix for the given text).

(b) A Turkish passage some parts of which deliberately included illformed lexical, syntactic and semantic structures to check if the students could identify and correct them. Actually, the passage was a badly translated text from English to Turkish.

(c) Students' own translations to find out whether individual mistakes are later detected and corrected, especially when they are no longer under the influence of the assumingly interfering English structures in the original text.

The materials mentioned in (b) and (c) aided the identification of LA levels of students in the mother tongue. To serve this end, we decided on three basic criteria for evaluation: The first one was the "appropriate lexical selection" in the Turkish text, which meant not only the transference of the meaning of the original word, but also the reflection of the socially and culturally accepted usage in natural discourse. The second criterion was the "syntactic wellformedness" of the Turkish sentence. Some of the student translations gave us the impression that their minds were heavily influenced by the English syntax, thus they either ended up with ill-formed Turkish structures that sounded unnatural or failed to employ helpful translation strategies. For this reason, grading the syntactic well-formedness of the Turkish sentences was considered to be essential. Finally, the third criterion used was the "semantic well-formedness" of the Turkish sentences. Interestingly enough, some of the translated sentences seemed to be syntactically well-formed, yet they were far from reflecting the original meaning fully. In contrast, some of the sentences which seemed to transfer the original meaning one way or another, lacked full syntactic well-formedness in Turkish. The researchers would draw the attention of students to the mistakes in their translated versions where necessary. All the tests were given on different days and, importantly, at least three days had to pass before the correction of their own translations. 


\subsection{Findings and Discussion}

This section provides the results obtained from each test and comparative evaluations concerning freshman and senior groups in each department are presented in tables. Statistical analysis was carried out with the SPSS program.

Table 1a: English Proficiency Test Results: Comparison of DL and DTI in General

\begin{tabular}{|l|l|l|l|l|l|}
\hline & Dept & $\mathrm{N}$ & Mean & St. Dev. & $\mathrm{t}$ \\
\hline \multirow{3}{*}{ Proficiency } & DL & 30 & 17,43 & 2,43 & \multirow{2}{*}{$-4,65 * *$} \\
\cline { 2 - 5 } & DTI & 30 & 19,77 & 1,28 & \\
\hline
\end{tabular}

$* * \mathrm{p}<0,01$

Table 1a demonstrates that a significant difference was found between the two departments in terms of the English proficiency test results. According to the previously determined criterion, the test results of DL students were not lower than 70; however, DTI students obtained comparatively higher scores. If the nature of this difference has to be discussed, we tend to relate it to the university entrance exam points, which matter for the selection of students to Turkish universities and their departments. In other words, those students who are hoping to enter DTI, Hacettepe University, have to collect higher points in English than those who wish to enter DL at the same university. Even if this consideration may not be valid in all cases, we still consider it as an important factor. However, as shown in Table $1 \mathrm{~b}$ and $1 \mathrm{c}$, it is interesting to note that there is no statistically significant difference between the total of the freshman and senior students of both departments. This may mean that the students of both departments do not actually display a striking improvement from the freshman to the senior group regarding their levels of English. Yet, one should also note that their proficiency levels were found satisfactory enough.

Table 1b: English Proficiency Test Results: Comparison of Freshman and Senior Groups in DL

\begin{tabular}{|l|l|l|l|l|l|}
\hline & Class & $\mathrm{N}$ & Mean & St. Dev. & $\mathrm{t}$ \\
\hline \multirow{2}{*}{ Proficiency } & senior & 15 & 18,20 & 1,47 & \multirow{2}{*}{1,79} \\
\cline { 2 - 5 } & freshman & 15 & 16,67 & 2,97 & \\
\hline
\end{tabular}

$* * \mathrm{p}<0,01$ 
Table 1c: English Proficiency Test Results: Comparison of Freshman and Senior Groups in DTI

\begin{tabular}{|l|l|l|l|l|l|}
\hline & Class & $\mathrm{N}$ & Mean & St. Dev. & $\mathrm{t}$ \\
\hline \multirow{2}{*}{ Proficiency } & senior & 15 & 19,80 & 1,37 & \multirow{2}{*}{0,14} \\
\cline { 2 - 5 } & freshman & 15 & 19,73 & 1,22 & \\
\hline
\end{tabular}

$* * \mathrm{p}<0,01$

Table 2a: Distribution of Translation Problems in DL and DTI: A General Comparison

\begin{tabular}{|l|l|l|l|l|l|}
\hline & Dept & $\mathrm{N}$ & Mean & St. Dev. & $\mathrm{t}$ \\
\hline \multirow{2}{*}{$\begin{array}{l}\text { Appropriate Lexical } \\
\text { Selection }\end{array}$} & $\mathrm{DL}$ & 30 & 16,70 & 2,04 & \multirow{2}{*}{$-3,78^{* *}$} \\
\cline { 2 - 5 } & $\mathrm{DTI}$ & 30 & 18,37 & 1,30 & \\
\hline \multirow{2}{*}{$\begin{array}{l}\text { Syntactic } \\
\text { Well-formedness }\end{array}$} & $\mathrm{DL}$ & 30 & 9,13 & 1,33 & \multirow{2}{*}{0,49} \\
\cline { 2 - 5 } & DTI & 30 & 8,97 & 1,30 & \\
\hline \multirow{2}{*}{$\begin{array}{l}\text { Semantic } \\
\text { Well-formedness }\end{array}$} & DL & 30 & 8,30 & 1,49 & \multirow{2}{*}{$-5,61^{* *}$} \\
\cline { 2 - 5 } & DTI & 30 & 9,87 & 0,35 & \\
\hline
\end{tabular}

$* * \mathrm{p}<0,01$

Table $2 \mathrm{a}$ above shows a significant difference between the two departments to the advantage of DTI students in general. In terms of the translation evaluation criteria, DL students displayed a significantly higher value only in syntactic well-formedness. We assume this difference can be related to the fact that DL students, who follow most of the courses in English and who are given extensive education on comparative syntax, were more cautious with the syntactic structures, yet they could not display an equal degree of semantic well-formedness in their sentences at the same time. As far as the selection of appropriate lexical items is concerned, DTI students performed better. However, there were problem words for both groups of students. For example, the word "sceptical" in the sentence "This is a sceptical age" (see line 1 in the original text given in Appendix) was one of those problem words, because this word can take a variety of suffixes in Turkish, each referring to some other referent with different meanings. The common error made here was that the word chosen by most students in Turkish was the word "şüpheci", giving the meaning to the whole sentence "this is a suspicious age" in English. On the other hand, the word "modern" in line 4 is a borrowed word used in Turkish; yet, the word "modern" in the phrase "this 
modern faith in a bottle of medicine" should have been translated into Turkish in phrase structure consisting of more than two words in such a way to mean "current" in English; however, the students chose to use it as it is, which distorted the intended meaning. Although DTI students were found to have applied this translation strategy significantly better than DL students, the mean value shows that not all students were successful enough in doing so, which must be marked by the translation teachers. On the other hand, it has to be noted that the mean value for the freshman students, disregarding whether it is significant or not, is higher than that of the senior students. Though it may not have been well reflected in the statistical results, it has drawn our attention to the fact that the freshman students were less distracted by the structure of the source language and were freer to make lexical selections, which were semantically more appropriate. The question we asked ourselves was whether the teaching of the translation strategies in DTI or the concentration on the English syntax in DL had a rather negative effect of timidity on students.

Table 2b: Distribution of Translation Problems: Comparison of Freshman and Senior Groups in DL

\begin{tabular}{|l|l|l|l|l|l|}
\hline & Class & $\mathrm{N}$ & Mean & St. Dev. & $\mathrm{t}$ \\
\hline $\begin{array}{l}\text { Appropriate Lexical } \\
\text { Selection }\end{array}$ & senior & 15 & 17,07 & 2,40 & \multirow{2}{*}{0,97} \\
\cline { 2 - 5 } & freshman & 15 & 16,33 & 1,59 & \\
\hline \multirow{2}{*}{$\begin{array}{l}\text { Syntactic } \\
\text { Well-formedness }\end{array}$} & senior & 15 & 9,40 & 0,74 & \multirow{2}{*}{1,10} \\
\cline { 2 - 5 } & freshman & 15 & 8,87 & 1,73 & \\
\hline $\begin{array}{l}\text { Semantic } \\
\text { Well-formedness }\end{array}$ & senior & 15 & 8,45 & 1,19 & \multirow{2}{*}{0,61} \\
\cline { 2 - 5 } & freshman & 15 & 8,13 & 1,77 & \\
\hline
\end{tabular}

$* * \mathrm{p}<0,01$

Table $2 \mathrm{~b}$ demonstrates that there is no significant difference between the senior and freshman classes of DL at any level; however, when the mean values are compared, it is observed that the mean values of the senior students are comparatively higher than those of the freshman students. 
Table 2c: Distribution of Translation Problems: Comparison of Freshman and Senior Groups in DTI

\begin{tabular}{|l|l|l|l|l|l|}
\hline & Class & $\mathrm{N}$ & Mean & St. Dev. & $\mathrm{t}$ \\
\hline \multirow{2}{*}{$\begin{array}{l}\text { Appropriate Lexical } \\
\text { Selection }\end{array}$} & senior & 15 & 17,93 & 1,58 & \multirow{2}{*}{$-1,91$} \\
\cline { 2 - 5 } & freshman & 15 & 18,80 & 0,77 & \\
\hline \multirow{2}{*}{$\begin{array}{l}\text { Syntactic } \\
\text { Well-formedness }\end{array}$} & senior & 15 & 8,33 & 1,54 & \multirow{2}{*}{$-3,02 * *$} \\
\cline { 2 - 5 } & freshman & 15 & 9,60 & 0,51 & \\
\hline \multirow{2}{*}{$\begin{array}{l}\text { Semantic } \\
\text { Well-formedness }\end{array}$} & senior & 15 & 9,87 & 0,35 & \multirow{2}{*}{0,00} \\
\cline { 2 - 5 } & freshman & 15 & 9,87 & 0,35 & \\
\hline
\end{tabular}

$* * \mathrm{p}<0,01$

As Table 2c displays, a significant difference was found only at the syntactic well-formedness level to the advantage of the freshman students, which may imply that freshman students were better in producing appropriate sentence structures in Turkish. Yet, the fact that there is no difference between the freshman and senior classes for the criterion of semantic well-formedness implies that forming structurally acceptable sentences does not always help a significant value appear at the semantical level.

Table 3a: General Comparison of LA performances in DL and DTI

\begin{tabular}{|l|l|l|l|l|l|}
\hline & Dept & $\mathrm{N}$ & Mean & St. Dev. & $\mathrm{t}$ \\
\hline $\begin{array}{l}\text { Language } \\
\text { Awareness }\end{array}$ & $\mathrm{DL}$ & 30 & 4,93 & 2,18 & \multirow{2}{*}{$-6,57 * *$} \\
\cline { 2 - 5 } & DTI & 30 & 9,00 & 2,60 & \\
\hline
\end{tabular}

$* * \mathrm{p}<0,01$

Table 3a shows that a significant difference was found in terms of LA between the students of the two departments to the advantage of DTI.

Table 3b: LA Performances: Comparison of Freshman and Senior Groups in $D L$

\begin{tabular}{|l|l|l|l|l|l|}
\hline & Dept & $\mathrm{N}$ & Mean & St. Dev. & $\mathrm{t}$ \\
\hline \multirow{2}{*}{$\begin{array}{l}\text { Language } \\
\text { Awareness }\end{array}$} & senior & 15 & 5,07 & 2,74 & \multirow{2}{*}{0,33} \\
\cline { 2 - 5 } & freshman & 15 & 4,80 & 1,52 & \\
\hline
\end{tabular}

$* * \mathrm{p}<0,01$ 
As Table $3 b$ displays, no statistically significant difference was detected between the senior and freshman classes of DL; however, it should be noted that the mean value for the senior students is comparatively higher than that of the freshman students. Regarding the scores of DTI students shown in Table $3 \mathrm{c}$ below, it can be inferred that, in comparison to DL students, LA levels of the senior DTI students have developed much better during the 4-year translation training period.

Table 3c: LA Performances: Comparison of Freshman and Senior Groups in DTI

\begin{tabular}{|l|l|l|l|l|l|}
\hline & Dept & $\mathrm{N}$ & Mean & St. Dev. & $\mathrm{t}$ \\
\hline $\begin{array}{l}\text { Language } \\
\text { Awareness }\end{array}$ & senior & 15 & 10,13 & 2,53 & $2,62 * *$ \\
\cline { 2 - 5 } & freshman & 15 & 7,87 & 2,20 & \\
\hline$* * \mathrm{p}<0,01$
\end{tabular}

As mentioned before, after at least a three-day period, all groups of students were asked to have a look at their own translations once again and revise them under the supervision of the researchers. While some of the students could detect their mistakes, most needed the consciousness-raising remarks of the researchers. In either case, we found that a good number of students, acknowledging their mother tongue mistakes, expressed their surprise at their "carelessness", giving us the impression that a temporary interruption of LA might have been the case during the active process of translation. Unfortunately, we do not have a statistical analysis for the self-checks of the students in the classroom environment. This observation, however, should not be taken as if all the students were highly conscious of their mother tongue. There were certain students in both departments who gave us the impression that they needed some real LA instruction. On the other hand, as the following examples will illustrate, there were some common problems found in the students of both departments. Depending on the LA problems observed in their translated texts and in the Turkish text given for correction, we observed that they had problems related to each of the three criteria considered. Here are only a limited number of examples out of many others:

(a) In the Turkish text given for correction which included deliberately inserted ill-formed structures, one of the sentences was "Böyle adamlar her toprakta yetismiyor", meaning "Such men don't grow on every bush" in English. The given Turkish sentence, which was a word-to-word translation of the English original, was expected to be corrected by the students, for no native speaker of Turkish would make such a sentence in his natural discourse. Depending on the context of the text, the expected corrections would be either "Böyle adamlar her zaman bulunmuyor" (Such men are not always found) or "Böyle adamlar nadir bulunur" (Such men are seldom found). Although this sentence was not an easy one for the 
freshman or for the senior students in both departments, DTI students were still comparatively much better in coping with the difficulty, either because of various translation techniques they have been taught or because of their individually better levels of LA. Due to the fact that DL students are given a limited number of translation courses during the undergraduate program, they are not as good as DTI students in the employment of translation strategies. Another reason may be their lower level of LA.

(b) Another example from the above mentioned text was "Birkaç havucumuzun olmayışı çok kötü!”, meaning “Too bad, we don’t have a few carrots!" in English. Normally, in an exclamatory sentence of this sort, a Turkish speaker would say, "Biraz havucumuzun olmaması da ne kötü!" (How bad it is ../ What a bad thing it is../ What a pity that we don't have some carrots!).

(c) An example from the lexical problems goes like this: Again in the same text, the students were given the sentence "Korkarim $k i$, sen böbürleniyorsun", meaning "I am afraid you are boasting". Unfortunately, "Korkarım ki", which is the mechanical translation of the English expression "I am afraid", is one of the examples that has been unconsciously adopted and is used by the Turkish speakers as a result of the badly translated language of many TV serials. For this reason, few students could detect this as a problem. On the other hand, no natural Turkish discourse would let the whole meaning be uttered as in the sentence given above. Instead, the students could write something more natural like, "Bence sen de kendini amma beğeniyorsun" ("In my opinion, you like yourself too much"). Nevertheless, the number of students who wrote the same or similar sentences as corrections was quite limited.

(d) In the translation text, the sentence "The doctor in charge of the department is only too ready to provide them with these requirements" (highlighted in the translation text) was a problem for most of the students, not because of the difficulty of its English structure, but because of its semantically and syntactically well-formed transference to Turkish. The observation is that DTI students, especially the senior ones, were again comparatively better since they knew what translation strategy they could use for this sentence.

(e) As a final example, a lexical problem in the correction text was noteworthy: One of the sentences, which deliberately included an inappropriate word, was "Generallere layı bir çorba bu", meaning "This soup fits for a general" in English. Although all Turkish speakers would use the word "kral" (king) instead of the word 
"general" in such a sentence, it was interesting to observe that few students made the expected correction in their written versions. However, during the classroom revision and correction session almost all students reacted to this usage and self-corrected, not believing what they had written. This was one of the typical examples of the interruption or blockage of LA.

\section{Conclusion}

Within the limits of this paper, we tried to illustrate that it is possible for translators (in our case, DL and DTI students at Hacettepe University, Ankara) to undergo a process of interruption of LA during translation. It has been observed that in cases where interruption is not the basic reason for the poor quality translations, the problem is closely related to the low level of LA in the mother tongue. Instruction of translation strategies may help to overcome such problems to a certain degree; however, making full benefit of the theoretical instruction is possible only when LA in the mother tongue is activated.

Comparing the freshman and senior students of both departments, we saw that DTI students obtained statistically better translation scores than DL students did. DL students had comparatively more ill-formed Turkish structures, accompanied by inappropriate lexical selections in their translations and with the exception of a limited number of students, could not successfully make mother tongue corrections in general. The reason must be related to the fact that their concentration on the English structures is stronger and little or no LA instruction is provided. Those who were individually interested in reading, for example, or who individually developed a better language sensitisation were the exceptional cases. On the other hand, the number of such students in DTI was clearly higher. In this case, we thought that translation training, which also employed Turkish, provided them with somewhat better LA levels. Nevertheless, this level of performance was still far from the desired level. Classroom revision and correction sessions proved that consciousness-raising activities were quite beneficial for the students. Although translation criticism courses given in DTI are helpful in this respect, the emphasis on the development of LA needs to be reinforced. Likewise, DL students, who mainly concentrate on different branches of linguistics in English, thus, spend less time on the development of LA in their courses, also need such reinforcement. To this end, mother tongue sensitisation practices are highly recommended for students. While LA development can be recommended for all native speakers within the context of education, functional literacy, and language planning, the case for foreign language speaking and translating natives is even more important, because badly and hastily made translations can interfere with the linguistic characteristics and the correct use of the mother tongue, especially when people frequently hearing or reading such examples, for example, in written or oral forms of discourse taking place in media, get used to them in time. Established mis- 
takes may sound more natural, which, consequently, threatens the purity and the future quality of the mother tongue. This is presently an observed phenomenon in Turkish. For this reason, we seriously consider LA development in foreign language speaking and translating individuals as an important asset.

\section{Bibliography}

Anderson, J.R. (1995). Learning and Memory: An Integrated Approach. NewYork: Wiley.

Bernstein, B. (1971-75). Class, Codes and Control Vols.1-3. London: Routledge and Kegan Paul.

Bialystock, E. (1982). "On the Relationship between Knowing and Using Forms." Applied Linguistics 3, 181-206.

Donmall, B.G. (ed.) (1985). "Language Awareness.” NCLE Reports and Papers 6. London: Centre for Information on Language Teaching. English. London: Longman.

Gnutzmann, C. (1997). "Language Awareness: Progress in Language Learning and Language Education, or Reformulation of Old Ideas?" Language Awareness $6(2 \& 3), 65-74$.

Hawkins, E. (1984). Awareness of Language: An Introduction. Cambridge: Cambridge University Press.

Krashen, S. (1979). "The Monitor Model for Second Language Acquisition." R. Gingras (ed.) (1979). Second Language Acquisition and Foreign Language Teaching. Washington, DC: center for Applied Linguistics.

Krashen, S. (1981). Second language Acquisiton and Second Language Learning. Oxford: Pergamon.

Krashen, S. (1985a). The Input Hypothesis: Issues and Implications. Harlow: Longman.

Krashen, S. (1985b). Language Acquisiton and Language Education. Englewood Cliffs, NJ: Prentice Hall.

Labov, W. (1972). Sociolinguistic Patterns. Philadelphia: University of Pennsylvania.

Little, D. (1997). "Language Awareness and the Autonomous Language Learner." Language Awareness 6 (2\&3), 93-104.

Multhaup, U. (1997)."Mental networks, Procedural Knowledge and Foreign Language Teaching." Language Awareness 6 (2\&3), 75-92.

Walker, K. (1970). "Patients and Doctors." L.C. Alexander (ed.) (1970). Fluency in English. London: Longman.

\section{Appendix:}

The following is the original text presented to students for translation:

This is a sceptical age, but although our faith in many of the things in which our forefathers fervently believed has weakened, our confidence in the curative properties of the bottle of medicine remains the same as theirs. This modern faith in medicines is proved by the fact that the annual drug bill of the Health Services is mounting to astronomical figures and shows no signs at present of ceasing to rise. The majority of the patients attending the me- 
dical out-patients departments of our hospitals feel that they have not received adequate treatment unless they are able to carry home with them some tangible remedy in the shape of a bottle of medicine, a box of pills, or a small jar of ointment, and the doctor in charge of the department is only too ready to provide them with these requirements. There is no quicker method of disposing of patients than by giving them what they are asking for, and since most medical men in the Health Services are overworked and have little time for offering time-consuming and litlle-appreciated advice on such subjects as diet, right living, and the need for abandoning bad habits, etc., the bottle, the box, and the jar are almost always granted them.

Kenneth Walker, Patients and Doctors 